\title{
Restorative Justice and the School-to-Prison Pipeline: A Review of Existing Literature
}

\author{
Hani Morgan (D)
}

Citation: Morgan, H. Restorative Justice and the School-to-Prison Pipeline: A Review of Existing Literature. Educ. Sci. 2021, 11, 159. https://doi.org/10.3390/ educsci11040159

Academic Editor: Garry Hornby

Received: 1 February 2021

Accepted: 30 March 2021

Published: 31 March 2021

Publisher's Note: MDPI stays neutral with regard to jurisdictional claims in published maps and institutional affiliations.

Copyright: (C) 2021 by the author. Licensee MDPI, Basel, Switzerland. This article is an open access article distributed under the terms and conditions of the Creative Commons Attribution (CC BY) license (https:// creativecommons.org/licenses/by/ $4.0 /$ )
School of Education, University of Southern Mississippi, Hattiesburg, MS 39406, USA; Hani.Morgan@usm.edu

\begin{abstract}
Black students experience out-of-school suspensions at a higher rate than other students. The higher rate at which these students are suspended is believed to contribute to a school-to-prison pipeline. This review article is designed to enhance the understanding of this problem by focusing on the factors that play a part in the school-to-prison pipeline. A purposeful sample of recently published literature by some of the leading scholars in this area was selected for analysis. Some studies indicate that school personnel may be biased in the ways they respond to Black students. The lack of teacher preparation and support has been documented to be one of the contributing factors as well. Researchers have also referred to the similarities between urban schools and other schools with high concentrations of Black students, arguing that these schools implement more punitive approaches to discipline. This review article enhances the understanding of a possible way to deal with this problem by including content about how implementing effective restorative discipline programs may alleviate the school-to-prison pipeline.
\end{abstract}

Keywords: school discipline; inequalities in education; restorative justice

\section{Introduction}

In 2020, the killing of George Floyd by the police was viewed all over the world after bystanders captured video of this incident. Tens of thousands of people in over 100 U.S. cities protested after the death of Mr. Floyd, leading the National Guard to be called in at least 21 states [1]. The protests were a response to how certain racial minority groups were being treated. The disproportionate rates at which Black people are incarcerated in the United States reflect the biased methods that contribute to their arrests and convictions. These methods include stopping and searching them more often. Critics of America's judicial system have frequently referred to how the enforcement of drug laws reflects this poor treatment. Although Black people use drugs at similar rates to those of people from other groups, they are prosecuted at much higher rates [2]. The biased methods of searching, arresting, and convicting Black people are not the only factors researchers refer to for explaining the high incarceration rates members of this group endure. The punitive form of school discipline many Black students experience is believed to contribute to a school-to-prison pipeline. Urban schools and other schools with high percentages of minority students are more likely to implement this harsh style of discipline, leading these students to experience higher rates of out-of-school suspension [3]. The term "urban school" is often used to describe schools according to their geographic locations. However, this term is also used to describe schools according to economic, social, and educational factors. It is not unusual for this term to be used for referring to schools in relation to the poverty levels of the student population and the racial and ethnic diversity within the school [4].

Eliminating the punitive approach to discipline many schools implement is crucial because the disproportionate imprisonment of Black people is detrimental to all Americans. The increasing number of people who have been incarcerated in recent decades causes more money to be spent on creating and maintaining prisons, leaving less dollars that 
could be spent to better serve Americans. Research suggests that implementing welldesigned restorative discipline programs in schools with high percentages of minority students is a promising approach that may reduce the disproportionate imprisonment of Black people [5]. Some researchers provide convincing evidence showing that the punitive approach to school discipline many schools implement creates more chances for Black students to get in trouble with law enforcement personnel [6]. This review article contributes to the understanding of the school-to-prison pipeline by focusing on the factors that lead to this problem and also includes content on how an approach to justice may mitigate this concern. A purposeful sample of recently published literature by some of the leading scholars in this area was chosen to document the problem and the theories explaining how implementing restorative justice programs may alleviate this concern.

\section{Higher Rates of School Suspension}

According to the National Center for Education Statistics [7], Black students experience out-of-school suspensions at higher rates than any other group. As Figure 1 shows, in $2013-14,13.7 \%$ of Black students received out-of-school suspensions, but only $3.4 \%$ of White students did.

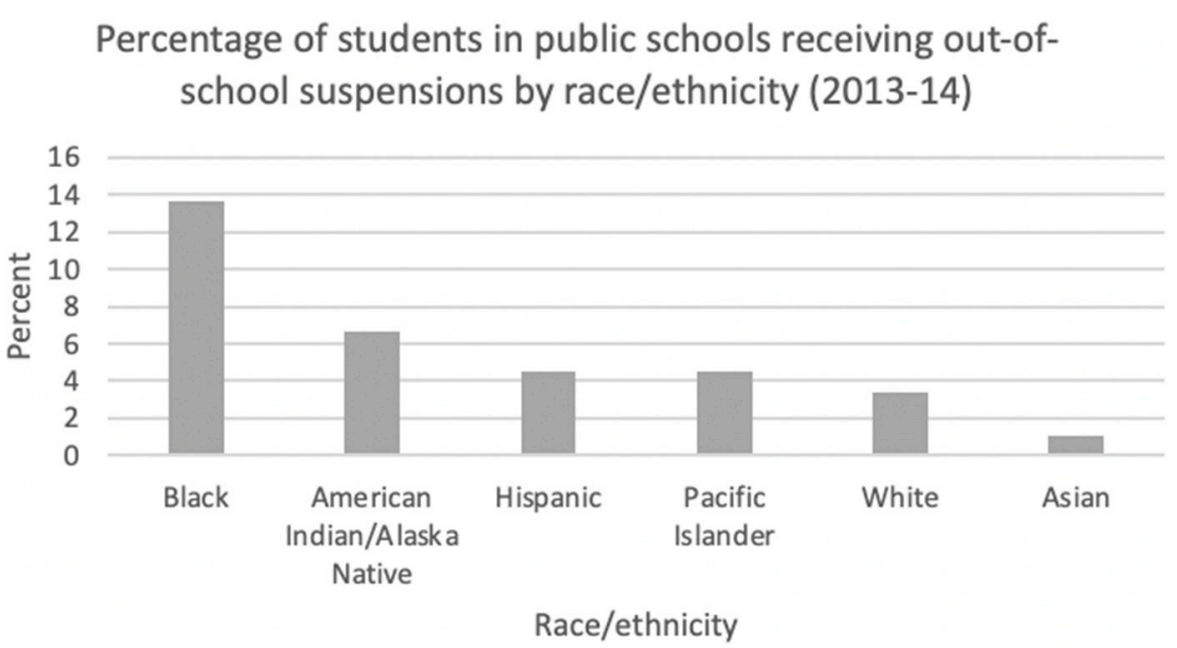

Figure 1. Source: National Center for Education Statistics (2019).

Although students from other racial minority groups receive higher-than-average percentages of suspensions, the rate at which Black students receive this form of punishment is much higher than average. The percentage of Black students who received out-of-school suspension in 2013-14 was almost twice as high as the percentage of the next highest racial group. The U.S. Department of Education [8] indicated that Black K-12 students were 3.8 times more likely to receive out-of-school suspensions than White students.

The higher rate at which Black students are suspended is believed to contribute to a school-to-prison pipeline for several reasons. First, out-of-school suspensions contribute to an increase in unsupervised time. Suspending students removes them from an environment with structured school supervision, increasing their opportunities to become involved in criminal activity. To investigate whether out-of-school suspensions were associated with crime, Cuellar and Markowitz [9] analyzed data from a school district and a juvenile justice system and mentioned that out-of-school suspensions may more than double the probability of arrest. Other researchers discussed that students who get suspended are much more likely to be arrested [6].

Second, suspensions contribute to a loss of instructional time. This loss makes it more difficult for students to succeed academically. Noltemeyer, Ward and Mcloughlin [10] conducted a meta-analysis to examine the association between suspensions and academic achievement. Their results showed an inverse relationship between suspensions and 
achievement. Academic failure is strongly associated with dropping out of school and future incarceration [3].

\section{Factors Contributing to the School-to-Prison Pipeline}

Research indicates that a variety of factors contribute to the school-to-prison pipeline. Some studies indicate that school personnel may be biased in the ways they respond to Black students [11,12]. The lack of teacher preparation and support has been documented to be one of the contributing factors as well $[13,14]$. Researchers have also referred to the similarities between urban schools and other schools with high concentrations of Black students, showing that schools with high concentrations of Black students implement more punitive approaches to discipline [3,15]. Finally, living in poverty increases the chances that Black students will endure the effects of institutional discrimination associated with the American educational system [16]. These effects involve attending schools with more uncredentialed and inexperienced teachers [17].

\subsection{Biased School Personnel}

One of the studies exploring the reasons Black students receive a higher percentage of suspensions indicated that school leaders held biases toward these students. The researchers found that Black students had a higher chance of being labeled troublemakers than White students for participating in the same behavior. They suggested that future efforts to reduce the school-to-prison pipeline need to focus on principals since they are the ones making the final decisions on suspensions and expulsions [12].

Like the study on principals, studies on teachers' attitudes suggest that they frequently hold biased views as well. A recent study, for example, indicated that Black teachers hold less anti-Black/pro-White implicit bias than White teachers. The researchers found that in counties with stronger anti-Black/pro-White implicit and explicit bias, larger racial disparities in suspension rates existed. They indicated that implicit biases can contribute to racial disparities in school discipline outcomes by influencing the manner in which educators interpret students' behaviors [11]. These findings are significant because there is a shortage of Black teachers in the public school system. Although minority students in K-12 schools in the United States constitute over $40 \%$ of all elementary and secondary students, minority elementary and secondary teachers constitute less than $20 \%$ of all teachers [18].

Another recent study focused on comparing racial bias between teachers and nonteachers to investigate whether teachers perpetuate racial inequality in schools. The researchers investigated teachers' explicit and implicit racial bias and compared it to the level of bias adults with similar characteristics hold. This was a notable study because schools are sometimes thought of as democratic institutions designed to teach students how to participate equitably in society. However, the researchers found that both teachers and nonteachers held pro-White racial biases and that any differences between the two groups were insignificant [19]. Their findings suggest that teachers need more training to lessen their racial biases if schools are expected to function as institutions that promote racial equality.

The biases teachers may have toward students of different races can occur as soon as children interact with their first teacher. A research brief published by the Yale University Child Study Center indicated that even during the preschool years, teachers are likely to have biases toward Black children. The researchers recruited early educators and had them complete two tasks. One task required the participants to watch videos of preschoolers as their eye gazes were tracked. The participants watched videos of preschoolers from different backgrounds engaging in normal activities. They were prepared to view challenging behavior, although none existed. The results revealed that the teachers gazed longer at the Black children, especially the Black boys. They concluded that the tendency to observe Black children more closely may contribute to the documented race disparities in preschool expulsions and suspensions [20]. 
One of the reasons teachers may be biased when responding to Black students involves misinterpretations. As previously mentioned, teachers in American schools are predominantly White, but students of color constitute almost half of the student population. The difference in cultural experiences between Black students and White teachers contributes to misunderstandings that prevent these students from learning. Teachers can avoid misunderstandings by developing knowledge of students' cultural backgrounds and developmental needs [21]. Too many teachers adopt a color-blind ideology, ignoring how belonging to a certain racial group affects students' lives. For example, teachers may not confirm the biased institutional practices that occur in today's schools that lead to the high suspension rates of African American males [3].

\subsection{Lack of Teacher Preparation and Teacher Support}

Teacher bias toward Black students can be minimized by providing strong teacher preparation programs that adequately address topics about the education of students from diverse backgrounds. Equally important is including professional development sessions designed for reducing expulsion and suspension rates. Unfortunately, research on the extent to which teachers receive such support and preparation indicates that they lack training in this area [3]. Teachers are frequently not explicitly taught to develop culturally responsive instructional practices and materials. Consequently, they often perceive students living below the poverty line as deficient. This view leads them to ignore the special ways students from marginalized families learn and behave. They may even look down upon outcomes associated with poverty such as tardiness and chronic absenteeism [3].

These kinds of attitudes are antithetical to those properly trained teachers need to have. Some of the fundamental beliefs for teaching students from diverse cultures equitably include respecting their cultural differences, promoting democratic values in school, and creating an environment that supports multiculturalism. Culturally sensitive educators understand how discrimination, sexism, and prejudice affect students and their families. They also instruct students using a curriculum that reflects these beliefs [22].

One reason many teachers lack the skills to provide the education Black students deserve involves the lack of emphasis teacher preparation programs devote to preparing teachers to interact with students from diverse cultures. Research has revealed that many teachers lack confidence about their abilities to work with diverse students and that one of the factors contributing to this problem is the lack of preparation associated with the college programs they complete [23]. In one study, for example, researchers investigated 14 southeastern public institutions with teacher education programs and found that only four required students to take $20 \%$ or more of their courses with an explicit multicultural component [14].

Regarding professional development, schools typically implement short workshops led by experts. These workshops tend to be ineffective in promoting the changes needed to reduce disproportionate discipline rates. Effective professional development produces better outcomes. Several studies on a teacher-coaching program, for example, indicated that it produced impressive results. These studies investigated the effects of the My Teaching Partner Secondary program. A randomized controlled trial (RCT) showed that this program led to student achievement gains. A subsequent RCT revealed that after one year of coaching, teachers lowered the discipline gap between Black students and those from other racial groups [13].

\subsection{Punitive Systems of High-Minority Schools}

The discipline systems in many urban schools with high concentrations of Black students contribute to the school-to-prison pipeline in various ways. These schools usually contain more police officers and less guidance personnel than other schools. Between 1975 and 2008, a large increase in the percentage of police officers assigned to work in schools occurred. The majority of these officers, called school resource officers (SROs), were placed in urban schools with large percentages of students of color. This increase is significant 
since behaviors once handled by school personnel became referred to the police, increasing the criminal penalties students receive [24]. The primary role of the police in schools is to enforce criminal laws. Any violation of a school rule can be regarded as a criminal violation when viewed first by the police [25].

In addition to an increase in the number of SROs and security guards, urban schools have added more surveillance tools, such as cameras. Urban schools are more likely to implement stricter dress codes, require students to have identification, control access to school grounds, and make students go through metal detectors [3]. The increase in security measures and security personnel make it more likely that students will be confronted for violating a school code. Another concern involves the inexperience of the security personnel who confront students. Many SROs are retired or current law enforcement officers who may lack adequate training in how to deal with young people. As a result, they may interpret disorderly conduct or insubordination as criminal acts and punish students more severely [3].

Other types of schools that contribute to the school-to-prison pipeline include alternative schools. African American students are at a higher risk of being transferred to these schools. In Kentucky, for example, Black students were found to be over two times more likely to be transferred to these schools than students from other groups [15]. Like many urban schools, alternative schools increase Black students' chances of interacting with the police. A high percentage of these schools partner with the juvenile justice system. These partnerships make it more likely for alternative schools to provide incriminating information to parole and probation officers. The police may also regard these schools as high-risk zones and monitor these areas more closely [15].

\subsection{Institutional Discrimination}

Institutional discrimination is associated with incarceration. The American educational system reflects the institutional discrimination Black people experience in society because Black students are much more likely to attend high-poverty schools with higher dropout rates [26]. This trend increases the chances these students will be incarcerated because dropping out of high school is associated with going to prison. Hanson and Stipek [27] indicated that dropouts are over three times more likely of being arrested than high school graduates. High-poverty, high-minority schools also hire more unqualified teachers. Such schools are about three times more likely to hire the least qualified teachers than low-poverty, low-minority schools [17]. This trend creates higher chances that students at these schools will be taught by teachers with inadequate knowledge on how to deal with the behaviors students raised in poverty frequently display [28]. These students experience high stress levels that often leads to angry, assertive behavior. Some teachers may perceive students behaving this way as disrespectful young people, but a more accurate explanation of this conduct involves the insecure relationships these students experience as a result of living in poverty [28]. In addition to creating stronger chances that teachers will misunderstand student behaviors, the hiring of more underprepared teachers means that students at high-poverty schools are less likely to receive the education that will prepare them for attending college. This practice contributes to the school-to-prison pipeline because postsecondary education is associated with incarceration. Statistics from the Center for American Progress indicate that only about $24 \%$ of people in federal prisons have received postsecondary education while $48 \%$ of the general population has attained this level [29].

\section{Restorative Justice in Schools}

Implementing restorative practices in schools instead of exclusionary discipline can make a dramatic difference in alleviating the high rates at which Black students are disciplined. For example, when six elementary and middle schools in Texas piloted restorative discipline programs in an attempt to deal with their suspension rates, they experienced a $70 \%$ reduction in in-school suspensions and a 77\% reduction in out-of-school suspen- 
sions [30]. However, for these programs to produce desired results, schools need to implement restorative discipline well. Starting a restorative justice program can be challenging because different types of programs exist. School leaders therefore need to be aware of the characteristics of the programs that produce the best results and avoid the pitfalls that blunt a program's effect [31]. Recent research suggests that effective restorative justice programs are embedded in the overall school culture. The most common goals for embedding restorative justice consist of establishing a tolerant, respectful, and supportive environment among students and staff. This environment needs to be characterized by active listening [6].

\subsection{Definition of Restorative Justice}

Restorative justice (RJ) is a philosophy designed to promote conflict resolution by permitting people to remedy the harm they caused. It allows those who have been harmed to express their views on what needs to be done to make things right [3]. RJ can be described as a growing social movement designed to establish non-punitive methods for avoiding and addressing harm and for responding to violations of legal and human rights [6]. The use of RJ in schools started after educators learned how it was being used in the criminal legal system. These educators implemented the principles of RJ within their educational contexts [5].

\subsection{Origins of Restorative Justice}

RJ originated in Native cultures. Native American philosophy and practice has focused more on healing than on punishment [32]. Native cultures in the regions of the Americas and the South Pacific have used an approach to conflict that emphasizes the wrongdoer's accountability. This approach focuses on a plan that allows offenders to repair the damage caused by their misconduct [6]. RJ emerged in the Western judicial system as an approach to deal with crime in a way that would meet the needs of the victims, repair the harm, and restore the relationships of all people affected by the crime. In school settings, RJ was initially implemented in a manner similar to the way it was used at correctional facilities. This approach emphasizes using restorative conversations, circle processes, and conferences involving the members affected by an incident. These conferences focus on a set of questions designed to investigate who was harmed and what needs to be done to repair the harm. In recent years, RJ has been implemented in a manner that emphasizes prevention and early intervention to create safe learning environments [5].

\subsection{Implementation of Restorative Justice in U.S. Schools}

RJ has grown in popularity as a result of the increasing awareness about the detrimental impact of zero-tolerance policies [6]. Zero-tolerance policies were first introduced during the 1980s to crack down on drug trafficking and abuse [3]. The increasing concern about school-based violent crimes led to the passage of the 1994 Guns Free Schools Act, which required the removal of any student with a firearm in school for at least one year [24]. Regrettably, after this act, schools started suspending students for non-dangerous behaviors. Today, some schools apply zero-tolerance policies for violations such as swearing and student failure to attend school [3]. Critics of exclusionary discipline say this approach is detrimental because it can fail to bring resolution to harmful situations. In contrast, RJ creates opportunities for more communication and for resolutions to problems without the use of exclusionary discipline. RJ includes community-building to strengthen relationships and lower the frequency of offenses [6].

Milner et al. [3] discussed that restorative measures can be viewed as a pyramid. At the foundation of the pyramid is the use of affective language. Educators use this type of language to encourage awareness of self, of one's actions, and of the chances for correcting behaviors before they develop into major problems. To develop students' social and emotional skills, educators can use affective questions and statements. The middle of the pyramid consists of circle processes. Teachers can use these processes to develop 
a sense of community and strong relationships among students. During this stage of RJ, students sit in chairs in a circle as a facilitator leads the meeting. The facilitator emphasizes that each student has a right to express his or her views and that students need to be honest, responsible, and compassionate. Conferences occur when someone has been harmed. To resolve conflicts, conferences are used to create the opportunity for students to meet face to face to discuss how they feel about the situation and what needs to be done to make things right again [3].

\subsection{Research on Restorative Justice}

Rigorous research on RJ programs is limited. For example, a meta-analysis published in 2017 indicated that out of 60 studies that were analyzed, only about $20 \%$ consisted of randomized controlled trials [33]. Although many reports about RJ indicate that it leads to positive outcomes, a large portion of the research lacks the validity needed to conclude that the implementation of RJ caused desirable outcomes. Fronius et al. [6] mentioned that only one rigorous experimental study on RJ had been published at the writing of their report. This study showed that a program called "Pursuing Equitable and Restorative Communities" caused a decrease in the time students spent in out-of-school suspensions and a $16 \%$ decrease in school-level suspension rates. This program also led to higher PSAT scores for 10th grade students and to decreases in the chances of students being placed in alternative school environments. Less favorable outcomes occurred as well, such as null effects on the chances of being arrested. The researchers also reported that there were reductions in academic performance among Black students at the elementary and middle school levels. It is important to note that the outcomes of the program were measured during a 2-year period and that this time span may have been too short since it typically takes RJ implementation four years for the desired impact of a program to occur [6].

One reason some programs may yield mixed results involves poor implementation. Gregory and Evans [5] mentioned that there is strong evidence suggesting that RJ can reduce racial differences in exclusionary discipline but that five kinds of poor implementation approaches undermine the positive outcomes RJ programs produce:

1. Top-down approaches that lack the values of RJ.

2. Approaches based on one restorative practice.

3. Colorblind approaches.

4. Approaches without adequate support.

5. Short-term and under-resourced initiatives.

Top-down initiatives are misaligned with RJ values when they are mandated to produce quick change. Although policy changes are often ineffective unless developed jointly, districts too frequently authorize changes without considering whether institutions are ready or willing to implement new programs. Proceeding this way may result in resistance and reluctant compliance. Like top-down initiatives, narrow approaches reduce the chances that the RJ program will yield positive outcomes. The problem with this type of approach is that when crucial components of RJ are ignored, it may lead one initiative to be at odds with another. Narrow programs frequently do not include enough participation from an important group. In contrast, a holistic approach considers how one initiative complements others and includes the participation of a wide range of groups. Examples of narrow approaches include those that overemphasize student participation while minimizing the importance of school personnel and those that emphasize hiring additional RJ personnel and police officers at the same time [5]. As previously mentioned, using a colorblind ideology is harmful. Unfortunately, RJ is sometimes implemented without considering the oppression and abuses of power that cultural minority students too often endure. Such an approach can reproduce inequality rather than reduce it. Regarding approaches lacking support, these programs are likely to fail simply because teachers are not provided with enough training, feedback, and coaching. Finally, research on short-term and under-resourced initiatives indicates that without adequate resources and sustained commitment, schools can lose the gains a program produces over the years. One 
study showed that partial commitment made little difference when compared with no implementation at all [5].

\subsection{Criticisms of Restorative Justice}

$\mathrm{RJ}$ is often criticized when this method is recommended for victims of violent crimes. For many victims of sexual assault or attempted murder, the thought of meeting face to face with the perpetrator causes great stress. Victims of violent crime often feel that having contact with the offender could lead to revictimization rather than lead to healing [34]. Another criticism of RJ programs relates to the narrow range of cases for which this approach can be applied. RJ may be an alternative to other ways for dealing with conflicts when the facts are uncontested and when those involved accept their roles as offender and victim. However, in many conflicts, there is a dispute regarding the facts involving the conflict and confusion regarding the roles of those involved [35]. Other criticisms involve the challenges associated with implementing effective programs.

Critics of RJ make good points about the harm victims of violent crime may experience when meeting face to face with a perpetrator and the kinds of cases for which RJ cannot be applied. However, some of the criticisms of RJ occur as a result of misunderstandings about this approach. Lyubansky [36] identified various criticisms and provided reasons showing how each one may involve misinformation about RJ. His insights on this topic may be valuable because he teaches courses on race and restorative justice at the University of Illinois, Urbana-Champaign. He also supports various organizations, including schools, in building a restorative infrastructure designed to deal with conflicts and evaluating the associated outcomes. He provided the following nine criticisms:

1. It consumes too much time.

$\mathrm{RJ}$ is indeed time consuming. However, it can be considered time efficient when educators and parents compare it to the time lost when students are disciplined through the ineffective methods many schools implement.

2. It is emotionally depleting.

Although circle meetings may seem draining, students and teachers frequently feel energized when they become aware of new perspectives. As a result, they often experience a greater sense of connectedness.

3. Teachers should not be involved in RJ.

While teachers need to teach, they also need to address conflict when it occurs. Otherwise, it will escalate. This does not mean teachers need to deeply engage with students each time a conflict occurs. Their plan can be as simple as engaging more deeply at a later time.

4. There is no accountability with RJ.

It is true that punishment is not part of RJ. However, this does not mean that RJ lacks accountability. When RJ is implemented, accountability occurs in the form of agreements intended to make things right.

5. Agreements are not checked or followed.

This may occur in a poorly implemented program. However, in a well-designed system, agreements are checked to ensure that they are carried out. If they are not carried out, it means changes need to be made.

6. RJ is not a valid approach.

Although rigorous research on RJ is in its infancy, some of the existing research is promising. It is true that some studies led to disappointing outcomes. However, such outcomes may occur because $\mathrm{RJ}$ is either implemented poorly or not implemented long enough.

7. Victims need to endure unfair treatment for participating in RJ. 
Victims are not forced to participate in restorative processes. However, they often desire to do so in order for those who harmed them to become aware of the consequences of their actions. Many victims want to have dialogue so that the harm can end.

8. Victims need to forgive those who caused the harm.

Victims do not have to forgive anyone. Although forgiveness is not a goal of RJ, victims sometimes forgive those who harmed them. The goals of RJ include producing mutual agreements and understanding.

9. RJ leads to resistance and resentment.

When RJ programs are implemented through an authoritarian, top-down approach, there will likely be resistance. However, this is not the way RJ is intended to be implemented. $R J$ is designed to be implemented in a manner that provides shared power.

\section{Conclusions}

The high incarceration rates Black people experience is a severe problem that needs to be dealt with well. Research on school discipline suggests that the punitive approach urban schools and other schools with high percentages of Black students implement contributes to this problem. Some of the other factors contributing to this problem include biased school personnel, a lack of teacher preparation and support, and the effects of institutional discrimination associated with the American educational system. One of the ways policymakers may consider for dealing with this problem is to implement effective RJ programs. Although rigorous research on RJ programs is in its infancy, the existing studies suggest that when these programs are implemented based on the recommendations of leading scholars, positive outcomes will likely occur. By authorizing the use of welldesigned RJ programs, American school leaders can take action that can alleviate a problem that has spiraled out of control in the 21st century.

Funding: This research received no external funding.

Institutional Review Board Statement: Not applicable.

Informed Consent Statement: Not applicable.

Data Availability Statement: Not applicable.

Conflicts of Interest: The author declares no conflict of interest.

\section{References}

1. Taylor, D.B. George Floyd Protests: A Timeline. 2021. Available online: https://www.nytimes.com/article/george-floyd-proteststimeline.html (accessed on 22 February 2021).

2. Drug Policy Alliance. The Drug War, Mass Incarceration and Race. 2018. Available online: https://drugpolicy.org/resource/ drug-war-mass-incarceration-and-race-englishspanish (accessed on 20 January 2021).

3. Milner, R.H.; Cunningham, H.B.; O'Connor, L.D.; Kestenberg, E.G. These Kids Are Out of Control: Why We Must Reimagine "Classroom Management" for Equity; Corwin Press: Thousand Oaks, CA, USA, 2019.

4. Schaffer, C.L.; White, M.; Brown, C.M. A Tale of three cities: Defining urban schools within the context of varied geographic areas. Educ. Urban Soc. 2018, 50, 507-523. [CrossRef]

5. Gregory, A.; Evans, K.R. The Starts and Stumbles of Restorative Justice in Education: Where Do We Go from Here? National Education Policy Center: Boulder, CO, USA, 2020.

6. Fronius, T.; Darling-Hammond, S.; Sutherland, H.; Guckenburg, S.; Hurley, H.; Petrosino, A. Restorative Justice in U.S. Schools: An Updated Research Review; The WestEd Justice \& Prevention Research Center: San Francisco, CA, USA, 2019.

7. National Center for Education Statistics. Status and Trends in the Education of Racial and Ethnic Groups 2018; U.S. Department of Education: Washington, DC, USA, 2019.

8. U.S. Department of Education. 2013-14 Civil Rights Data Collection: A First Look. 2016. Available online: https:/ /www2.ed. gov/about/offices/list/ocr/docs/CRDC2013-14-first-look.pdf (accessed on 10 February 2021).

9. Cuellar, A.E.; Markowitz, S. School suspension and the school-to-prison pipeline. Int. Rev. Law Econ. 2015, 43, 98-106. [CrossRef]

10. Noltemeyer, A.L.; Ward, R.M.; Mcloughlin, C. Relationship between school suspension and student outcomes: A meta-analysis. Sch. Psychol. Rev. 2015, 44, 224-240. [CrossRef] 
11. Chin, M.J.; Quinn, D.M.; Dhaliwal, T.K.; Lovison, V.S. Bias in the air: A nationwide exploration of teachers' implicit racial attitudes, aggregate bias, and student outcomes. Educ. Res. 2020, 49, 566-578. [CrossRef]

12. Jarvis, S.N.; Okonofua, J.A. School deferred: When bias affects school leaders. Soc. Psychol. Personal. Sci. 2020, 11, 492-498. [CrossRef]

13. Gregory, A.; Hafen, C.A.; Ruzek, E.; Mikami, A.Y.; Allen, J.P.; Pianta, R.C. Closing the racial discipline gap in classrooms by changing teacher practice. Sch. Psychol. Rev. 2016, 45, 171-191. [CrossRef] [PubMed]

14. King, E.; Butler, B.R. Who cares about diversity? A preliminary investigation of diversity exposure in teacher preparation programs. Multicult. Perspect. 2015, 17, 46-52. [CrossRef]

15. Hirschfield, P.J. The role of schools in sustaining juvenile justice systems inequality. Future Child. 2018, 28, 11-35. [CrossRef]

16. Morgan, H. The World's Highest-Scoring Students: How Their Nations Led Them to Excellence; Peter Lang Publishing: New York, NY, USA, 2018.

17. Morgan, H. Making America \#1 in education with three reforms. Clear. House 2020, 93, 5-11.

18. Morgan, H. The gap in gifted education: Can universal screening narrow it? Education 2020, 140, $207-214$.

19. Starck, J.G.; Riddle, T.; Sinclair, S.; Warikoo, N. Teachers are people too: Examining the racial bias of teachers compared to other American adults. Educ. Res. 2020, 49, 273-284. [CrossRef]

20. Gilliam, W.S.; Maupin, A.N.; Reyes, C.R.; Accavitti, M.; Shic, F. Do Early Educators' Implicit Biases Regarding Sex and Race Relate to Behavior Expectations and Recommendations of Preschool Expulsions and Suspensions; Yale University Child Study Center: New Haven, CT, USA, 2016.

21. Morgan, H. The lack of minority students in gifted education: Hiring more exemplary teachers of color can alleviate the problem. Clear. House 2019, 4-5, 156-162. [CrossRef]

22. Gollnick, D.M.; Chinn, P.C. Multicultural Education in a Pluralistic Society; Pearson Education: Upper Saddle River, NJ, USA, 2021.

23. Gayle-Evans, G.; Michael, D. A study of pre-service teachers' awareness of multicultural issues. Multicult. Perspect. 2006, 8, 44-50. [CrossRef]

24. Jones, E.P.; Margolius, M.; Rollock, M.; Yan, C.T.; Cole, M.L.; Zaff, J.F. Disciplined and Disconnected: How Students Experience Exclusionary Discipline in Minnesota and the Promise of Non-Exclusionary Alternatives; America's Promise Alliance: Washington, DC, USA, 2018.

25. ACLU. Bullies in Blue: Origins and Consequences of School Policing; American Civil Liberties Union: New York, NY, USA, 2017.

26. Hanford, E.U.S. High School Graduation Rate Is Up-But There's a Warning Label Attached. 2016. Available online: https:/ / www.washingtonpost.com/news/answer-sheet/wp/2016/10/27/u-s-high-school-graduation-rate-is-up-but-theresa-warning-label-attached/ (accessed on 22 February 2021).

27. Hanson, K.; Stipek, D. Schools V. Prisons: Education's the Way to Cut Prison Population; Stanford Graduate School of Education: Stanford, CA, USA, 2014.

28. Jensen, E. Teaching with Poverty in Mind; ASCD: Alexandria, VA, USA, 2009.

29. Bender, K. Education Opportunities in Prison Are Key to Reducing Crime; Center for American Progress: Washington, DC, USA, 2018; Available online: https://www.americanprogress.org/issues/education-k-12/news/2018/03/02/447321/educationopportunities-prison-key-reducing-crime/ (accessed on 2 February 2021).

30. Long, C. Restorative Discipline Makes Huge Impact in Texas Elementary and Middle Schools. 2016. Available online: https: //www.nea.org/advocating-for-change/new-from-nea/restorative-discipline-makes-huge-impact-texas-elementary-and (accessed on 10 February 2021).

31. Walker, T. Restorative Practices in Schools Work ... But They Can Work Better. 2020. Available online: https://www.nea.org/ advocating-for-change/new-from-nea/restorative-practices-schools-work-they-can-work-better (accessed on 20 February 2021).

32. Mirsky, L. Restorative Justice Practices of Native American, First Nation and Other Indigenous People of North America: Part One. 2004. Available online: https:/ / www.iirp.edu/news/restorative-justice-practices-of-native-american-first-nation-andother-indigenous-people-of-north-america-part-one (accessed on 5 February 2021).

33. Wilson, D.B.; Olaghere, A.; Kimbrell, C.S. Effectiveness of Restorative Justice Principles in Juvenile Justice: A Meta-Analysis; George Mason University: Fairfax, VA, USA, 2017.

34. Gaudreault, A. The Limits of Restorative Justice. 2005. Available online: https://www.victimsweek.gc.ca/symp-colloque/pastpasse/2009/presentation/arlg_1.html (accessed on 10 February 2021).

35. Hanan, E. Decriminalizing violence: A critique of restorative justice and proposal for diversionary mediation. N. M. Law Rev. 2016, 46, 123-170.

36. Lyubansky, M. Nine Criticisms of School Restorative Justice. Available online: https:/ /www.psychologytoday.com/us/blog/ between-the-lines/201903/nine-criticisms-school-restorative-justice (accessed on 15 February 2021). 